\title{
GAYA BAHASA DALAM KRITIK SOSIAL PADA LAGU-LAGU KARYA IWAN FALS
}

\section{LANGUAGE EXPRESSION AS SOCIAL CRITICISM ON IWAN FALS' SONGS}

\author{
Nurhayati Fokkaya \\ Kantor Bahasa Provinsi Maluku Utara \\ Jalan Wijaya Kusuma No. 81, Kota Baru, Ternate \\ Telepon 081342251088
}

\begin{abstract}
Iwan Fals' song lyrics are likely to present social realities. This is a way to express the criticism of injustice to the government. The research uses semantic theory to analyze Iwan Fals' lyrics of songs. The aim is to describe the meaning of social criticisms from those lyrics. The method is a qualitative method by using descriptive approach. The results of this study show social criticisms in the lyrics by Iwan Fals in the years of 1981-1995 describe the issues of corruption, law enforcement, poverty, unemployment, and collusion. To express them, the author uses the style of figurative language such as metaphor and personification. One of his criticisms can be seen in the lyrics, Tikus-tikur Kantor (1984), Galang Rambu Anarki (1981), Sarjana Muda (1981), Orang Pinggiran (1995), and Surat Buat Wakil Rakyat (1987).
\end{abstract}

Keywords: Language Style, lyrics, criticism

\begin{abstract}
Abstrak
Lirik lagu Iwan Fals sering menyajikan realitas sosial yang dialami oleh masyarakat. Perihal tersebut merupakan cara untuk menyampaikan kritik atas ketidakadilan yang dilakukan pemerintah terhadap rakyat. Penelitian menggunakan pendekatan teori semantik untuk menganalisis lirik lagu-lagu karya Iwan Fals. Penelitian ini bertujuan agar dapat mendeskripsikan makna kritik sosial yang ada pada lirik lagu tersebut. Metodenya adalah metode kualitatif dengan pendekatan deskriptif. Hasil penelitian ini menunjukkan bahwa kritik sosial dalam lirik lagu karya Iwan Fals pada tahun 1981-1995 mendeskripsikan masalah korupsi, penegak hukum, kemiskinan, pengangguran, dan kolusi. Cara pengarang mengungkap kritik tersebut dengan menggunakan gaya bahasa kiasan, seperti metafora dan personifikasi. Salah satu kritiknya terlihat pada lirik lagu Tikus-tikus Kantor (1984), Galang Rambu Anarki (1981), Sarjana Muda (1981), Orang Pinggiran (1995), dan Surat Buat Wakil Rakyat (1987).
\end{abstract}

Kata kunci: Gaya Bahasa, Lirik Lagu, Kritik

\section{Pendahuluan}

Lirik lagu merupakan ekspresi seorang pencipta lagu tentang suatu hal yang sudah dilihat, didengar, dan dialaminya (Nagakawa, 2000). Dalam mengekspresikan lirik lagu tersebut, pencipta lagu melakukan permainan katakata untuk menciptakan daya tarik terhadap lirik atau syairnya.

Permainan bahasa ini dapat berupa 
permainan vokal, gaya bahasa atau penyimpangan makna kata dan diperkuat dengan penggunaan melodi dan notasi musik yang disesuaikan dengan lirik lagunya sehingga pendengar semakin terbawa dengan apa yang dipikirkan pengarang.

Hal ini dapat dilihat pada musisi Iwan Fals yang lirik lagunya menggambarkan kondisi kehidupan sosial, baik di lingkungan masyarakat maupun pemerintahan. Cara Iwan Fals mengekspresikan hal tersebut dengan menggunakan ungkapan gaya bahasa kiasan yang berisi kritikan kepada pemerintah dan masyarakat. Ada beberapa tema kritik dalam lagu Iwan Fals, misalnya kritik terhadap menyempitnya lapangan kerja, kebijakan para penegak hukum, korupsi dalam birokrasi, dan kritik terhadap anggota dewan yang tidak memperjuangkan hakhak rakyat.

Salah satu ungkapan metafora yang digunakan untuk menggambarkan koruptor adalah kata tikus dan kata kucing untuk para penegak hukum. Di sini, Iwan Fals membandingkan dua hal yang mempunyai kesamaan sifat, yaitu antara perilaku_seseorang dan makhluk lain. Selain itu, Iwan Fals, melalui gaya bahasa personifikasi, mempersamakan generasi muda dengan kata matahari.

Penelitian dengan objek kajian pada lirik lagu karya Iwan Fals sudah dilakukan oleh Siti Aisah (2010) dalam tesisnya yang berjudul Metafora dalam Lagu Iwan Fals yang Bertemakan Kritik Sosial: Ungkapan Metafora dalam Lirik Lagu Iwan Fals Dilihat dari Aspek Semantik dan Eva Dadan Agustina (2004) dalam skipsinya yang berjudul Video Klip Sebagai Interprestasi Lirik Lagu (Analisis Semiotik Lagu 'Ancur' yang di Nyanyikan Oleh Iwan Fals). Penelitian-penelitian tersebut hanya mengambil satu lirik lagu Iwan Fals sebagai data, sedangkan Eva Dadan
Agustina menambahkan penggambaran pesan pada lirik lagu yang dipertegas dengan video klipnya agar penikmat musik mudah memahami apa yang dimaksudkan oleh pencipta.

Sementara itu, penelitian ini mencoba mendeskripsikan makna kritik sosial pada beberapa lirik lagu karya Iwan Fals yang lain dengan menggunakan pendekatan teori semantik dan analisis gaya bahasa. Objek penelitian ini adalah lirik lagu: Tikustikur Kantor (1984), Galang Rambu Anarki (1981), Sarjana Muda (1981), Orang Pinggiran (1995), dan Surat Buat Wakil Rakyat (1987).

Berdasarkan latar belakang di atas, rumusan masalah dalam penelitian ini adalah (1) bagaimana Iwan Fals menggunakan gaya bahasa untuk menyatakan kritik sosial pada pemerintah dan lembaga Negara? dan (2) makna apakah yang terkandung dalam kritikan lagu Iwan Fals?.

Tujuan penelitian ini adalah (1) mengetahui bentuk kritik sosial pada lirik lagu karya Iwan Fals dan (2) mendeskripsikan makna dalam lirik lagu karya Iwan Fals. Semantara itu, manfaat penelitian ini secara teoritis diharapkan dapat memberi gambaran pada kajian karya sastra yang menganalisis lirik lagu. Manfaat praktisnya, penelitian ini bisa membantu para pembaca dan pendengar lagu, agar mengetahui bentuk kritik dalam lirik lagu tersebut.

\section{Kajian Teori}

Teori yang digunakan dalam penelitian ini adalah teori semantik dalam mendeskripsikan makna-makna yang terkandung dalam lirik lagu. Semantik adalah cabang linguistik yang membahas makna, baik makna leksikal maupun makna gramatikal. Makna leksikal adalah makna suatu kata yang mempunyai referen yang dapat berdiri sendiri, sedangkan makna gramatikal adalah 
makna yang muncul setelah mengalami proses gramatika yang bergantung pada struktur kalimatnya. Jadi dengan semantik, kita dapat mengetahui apa yang dimaksud dengan makna, bagaimanakah wujud makna, apakah jenis makna, apa saja yang berhubungan dengan makna, apakah komponen makna, apakah makna berubah, mengapa makna berubah, apakah setiap kata hanya memiliki satu makna atau lebih, dan bagaimanakah agar kita mudah memahami sebuah kata.

\section{Metode Penelitian}

Metode yang digunakan dalam penelitian ini adalah metode kualitatif dengan pendekatan deskriptif. Data dalam penelitian ini berupa kata, kalimat yang terdapat pada teks lirik karya Iwan Fals. Pengumpulan data dilakukan dengan mendengarkan, membaca, kemudian mendeskripsikan teks dalam lirik lagu Tikus-tikus Kantor (1984), Galang Rambu Anarki (1981), Sarjana Muda (1981), Orang Pinggiran (1995), Surat Buat Wakil Rakyat (1987) karya Iwan Fals. Data Dianalisis berdasarkan kritik sosialnya dengan pendekatan semantik.

\section{Hasil dan Pembahasan 4.1 Latar Belakang Iwan Fals} Iwan Fals yang bernama lengkap Virgiawan Listanto lahir di Jakarta, 3 September 1961 adalah seorang penyanyi beraliran balada yang menjadi legenda hidup Indonesia. Lewat lagu-lagunya, Iwan Fals berusaha menyuarakan apa yang selama ini terjadi pada masyarakat Indonesia. Dalam lirik lagunya, Iwan Fals banyak mengkritik perilaku pemerintah yang tidak empati kepada kelompok marginal, misalnya, dalam Surat Buat Wakil Rakyat (SBWR), Orang Pinggiran (OP), Sarjana Muda (SM), Galang Rambu Anarki (GRA), dan Tikus-tikus Kantor (TTK). Iwan Fals mengekspresikan perasaan, harapan, aspirasi, cita-cita, terhadap ide-ide dan semangat yang mewarnai pergulatan zaman Orde Baru.

\subsection{Ungkapan Gaya Bahasa Tentang Kritik Sosial}

Kritik sosial dipahami sebagai sebuah bentuk komunikasi yang dikemukakan baik dalam bentuk tulisan maupun lisan. Kritik sosial berkenaan dengan masalah interpersonal yang bertujuan mengontrol jalannya sistem sosial. Untuk mengetahui masalah kritik sosial pada lirik-lirik lagu karya Iwan Fals, akan dijelaskan sebagai berikut.

\subsubsection{Korupsi}

Korupsi menurut Kamus Besar Bahasa Indonesia (KBBI) adalah penyelewengan atau penyalahgunaan uang negara (perusahaan dsb.) untuk keuntungan pribadi atau orang lain. Dalam prakteknya, korupsi lebih dikenal sebagai menerima uang yang ada hubungannya dengan jabatan tanpa ada catatan administrasinya. Kritik sosial dapat dilihat pada kutipan berikut.

\section{Kisah usang tikus-tikus kantor \\ Yang suka berenang di sungai yang kotor \\ Kisah usang tikus-tikus berdasi \\ Yang suka ingkar janji \\ Lalu sembunyi dibalik meja \\ teman sekerja \\ Di dalam lemari dari baja}

(TTK)

Pada kutipan di atas, pengarang menggunakan metafora pada kata tikus. Metafora adalah uangkapan gaya bahasa yang membandingkan suatu benda dengan benda lain karena mempunyai sifat yang sama atau hampir sama. Makna denotasi dalam kata tikus adalah binatang pengerat. Umumnya berwarna hitam dan kelabu, tetapi ada juga yang berwarna putih. Fisiknya berbulu, 
berekor panjang, dan pada rahangnya terdapat sepasang gigi seri berbentuk pahat. Adapun makna konotasi pada kata tikus adalah para koruptor.

Kutipan di atas mendeskripsikan sikap para koruptor yang sering menerima imbalan (suap) dari orang yang akan membutuhkannya. Koruptor diidentikkan dengan tikus yang suka pada lingkungan yang kotor, sama halnya dengan koruptor yang menyukai pekerjaan-pekerjaan kotor. Walaupun begitu, tikus pada lirik tersebut tidak difisikkan dengan orang yang berpenampilan kumuh, seperti gelandangan. Tikus pada lirik tersebut berpenampilan rapi (pejabat, pengusaha) tetapi memiliki sifat kotor (tercela). Dengan begitu, kata tikus oleh pengarang digunakan sebagai simbol koruptor.

\subsubsection{Penegakan Hukum}

Penegakan hukum merupakan salah satu usaha pencegahan, pemberantasan, dan penindakan setelah terjadinya pelanggaran hukum. Hal ini dapat dilihat pada kutipan berikut.

Kucing datang cepat ganti muka Segera menjelma bagai tak tercela Masa bodoh hilang harga diri

Asal tak terbukti ah...

tentu sikat lagi.

Tikus-tikus tak kenal kenyang

Rakus-rakus kepalang

Otak tikus memang bukan otak udang

Kucing datang

Tikus menghilang

(TTK)

Dalam kutipan di atas, pengarang menggunakan ungkapan metafora pada kata tikus dan kucing. Makna denotasi pada kata kucing adalah binatang yang rupanya seperti harimau kecil dan biasa dipelihara orang, sedangkan makna konotasi kata kucing ditujukan kepada para penegak hukum.

Kucing dan tikus berkaitan dalam rantai makanan. Kucing merupakan binatang yang salah satu makanannya adalah tikus. Selain sebagai sumber makanan, fungsi kucing dalam rantai makanan bertindak sebagai pengendali atau penyeimbang terhadap perkembangbiakan tikus (sumber makanan). Sama halnya dengan kucing dalam rantai makanan, penegak hukum berkewajiban dalam melakukan pencegahan dan pengamanan terhadap tindakan-tindakan melawan hukum. Adapun pengarang memilih kata kucing untuk disimbolkan sebagai penegak hukum karena pada realistasnya baik kucing maupun penegak hukum samasama mengawasi mangsanya, kucing mengawasi tikus dan penegak hukum mengawasi pelaku kriminal.

Kutipan tersebut menggambarkan tentang para koruptor tidak pernah puas dengan apa yang dihasilkannya. Mereka selalu menyiapkan ide hasil korupsinya ketika ada pemeriksaan. Caranya, diekspresikan sikap baiknya ketika ada pemeriksaan dari para penegak hukum. Padahal, korupsinya tersebut, sudah diketahui oleh teman di sekitarnya. Namun, ia tidak pernah peduli atas anggapan teman kepadanya, yang penting hasilnya itu tidak jadi temuan atau dikenakan sanksi hukum.

\subsubsection{Kemiskinan}

Kemiskinan artinya orang-orang yang tidak berharta atau serba kekurangan (berpenghasilan sangat rendah). Untuk mengatasi kemiskinan tersebut, harus ada perhatian serius dari pemerintah. Pada lirik lagu berikut, orang miskin hanya bisa bekerja untuk mendapatkan makan dan minum, tetapi untuk kebutuhan masa depan hidunya hanya jadi impian. 
Orang pintar tarik subsidi

Mungkin bayi kurang gizi

Cepatlah besar matahariku

Menangis yang keras janganlah

ragu

Tinjulah congkaknya dunia buat hatiku

Doa kami di nadimu

(GRA)

Kutipan lagu di atas menggunakan gaya bahasa personifikasi, yakni pada kata matahariku. Personifikasi adalah gaya bahasa yang membandingkan benda-benda tak bernyawa dan seakanakan bernyawa. Makna denotasi kata matahari dalam KBBI adalah benda angkasa atau titik pusat tata surya berupa bola berisi gas yang mendatangkan terang dan panas pada bumi saat siang hari, sedangkan makna konotasinya adalah generasi muda.

Matahari merupakan sumber penghidupan bagi makhluk hidup. Sebagai contoh, dengan bantuan matahari, tumbuhan dapat melakukan fotosintesis untuk kelangsungan hidupnya. Asumsi pengarang menyimbolkan matahari dengan generasi muda bahwa keduanya memiliki kesamaan sebagai pihak yang dapat diharapkan dalam hal perubahan. Pada tumbuhan, matahari berperan dalam mengubah karbondioksida dan air menjadi karbohidrat, sedangkan generasi muda diharapkan dapat mengubah kehidupan bangsa menjadi lebih baik. Para cerdik pandai sering mengatakan bahwa generasi muda memiliki semangat dan pemikiran yang segar untuk kemajuan suatu bangsa. Bahkan, presiden pertama Indonesia sempat melontarkan pameo: "berikan aku sepuluh pemuda (generasi muda), maka akan kutaklukkan dunia".

Kutipan di atas, mendeskripsikan kritik terhadap pemerintah yang kurang mempedulikan kesejahteraan rakyat.
Karena, sumbangan seharusnya diberikan pada orang yang tidak mampu, ternyata hanya dinikmati oleh orang-orang yang mengolahnya. Imbasnya banyak bayi kurang gizi. Untuk mengungkapkan masalah ini, generasi muda yang harus siap menyampaikan aspirasi rakyat kepada pemerintah.

\subsubsection{Pengangguran}

Pengangguran adalah istilah untuk orang yang tidak bekerja sama sekali atau orang yang sedang berusaha mencari pekerjaan. Pengangguran sering kali menjadi masalah dalam perekonomian karena, dengan adanya pengangguran, produktivitas dan pendapatan masyarakat akan berkurang sehingga dapat menyebabkan timbulnya kemiskinan. Perhatikan kutipan kutipan lagu berikut.

Engkau sarjana muda

Resah mencari kerja

Mengandalkan ijazahmu

Empat tahun lamanya

Bergelut dengan buku

Tuk jaminan masa depan

Langkah kakimu terhenti

Di depan halaman sebuah jawatan

Terjenuh lesu engkau melangkah

Dari pintu kantor yang diharapkan

Terngiang kata tiada lowongan

Untuk kerja yang didambakan

(SM)

Dalam kutipan di atas, pengarang menggunakan metafora alusi untuk mengacu pada kondisi bangsa ini yang memiliki banyak sarjana tetapi menjadi pengangguran. Pengarang mencoba mendeskripsikan seorang sarjana dengan perjuangan membawa ijazah dari kantor ke kantor untuk mencari pekerjaan. Tanggung jawab dari pemerintah terhadap pembukaan lapangan kerja 
dirasa masih minim. Kendatipun kuliah selama empat tahun dengan menekuni dan mendalami buku dalam perkuliahan, tujuannya untuk menjamin perencanaan kebutuhan masa depan hidupnya dengan bekerja ternyata sia-sia.

\subsubsection{Kolusi}

Kolusi artinya kerja sama rahasia untuk maksud tidak terpuji. Hal ini sering terjadi dalam dunia birokrasi. Misalnya, pejabat tinggi negara yang seharusnya menjadi panutan masyarakat ternyata ada yang menggunakan wibawa jabatannya. Perhatikan kutipan kutipan lagu berikut.

\section{Wakil rakyat kumpulan orang hebat \\ Bukan kumpulan teman-teman dekat}

Apalagi sanak family

(SBWR)

Dalam kutipan di atas, pengarang menyampaikan kritiknya dengan menggunakan ungkapan repetisi. Repetisi adalah gaya bahasa dengan jalan mengulang penggunaan kata atau kelompok kata tertentu. Pada lirik lagu tersebut, terdapat ungkapan-ungkapan kumpulan orang hebat dan kumpulan teman-teman dekat. Ungkapan kesatu memperlihatkan bahwa wakil rakyat merupakan himpunan orang terpilih yang pantas untuk memperhatikan nasib rakyat. Sementara ungkapan kedua, menunjukkan bahwa wakil rakyat merupakan himpunan kongkalikong antarteman. Pada ungkapan kedua, pengarang meyakini bahwa adanya praktik persengkongkolan (kolusi) sesama wakil rakyat (pada himpunannya tersebut) dalam menjalankan tugasnya. Bahkan, pengarang menambahkan bahwa persengkongkolan bukan lagi antarteman, tetapi sudah merambah ke antarkeluarga.
Selain itu, pada lirik lagu SBWR juga mendeskripsikan bahwa para wakil rakyat lebih mementingkan aspirasi antarteman dan antarkeluarga, bukan lagi mengutamakan aspirasi rakyat. Padahal, para wakil rakyat ini merupakan himpunan orang-orang terpilih yang akan memperjuangkan hak dan kesejahteraan rakyat. Perhatikan nukilan berikut.

Di kantong safarimu kami titipkan Masa depan kami dan negeri ini

Saudara dipilih bukan dilotre Meski kami tak kenal siapa saudara Kami tak sudi memilih para juara Juara diam, juara he'eh, juara ha... ha... ha...

(SBWR)

Dari kutipan di atas terlihat pengarang menyampaikan kritiknya kepada pemerintah dengan menggunakan ungkapan antitesis pada kata Saudara. Antitesis adalah gaya bahasa yang menghadirkan kelompok-kelompok kata yang berlawanan maksudnya. Kutipan tersebut mendeskripsikan makna sebuah kritik sosial terhadap kebijakan wakil rakyat yang harus tegas dalam mengambil keputusan terkait persoalan rakyat karena amanat yang diberikan kepada para wakil rakyat harus dijalankan sesuai dengan fungsi dan tanggung jawab mereka.

Wakil rakyat diberikan kepercayaan oleh rakyat yang memilihnya sebagai pemegang amanat untuk bijak menyikapi persoalanpersoalan yang berpihak terhadap kepentingan rakyat. Hal demikian tercermin pada kutipan lirik lagu berikut, Di kantong safarimu kami titipkan//Masa depan kami dan negeri ini, kutipan lirik lagu itu begitu jelas bahwa wakil rakyat yang di angkat oleh rakyat melalui pemilihan umum diberikan harapan oleh 
rakyat untuk tegas mengambil keputusan yang adil dan amanat.

\section{Kesimpulan}

Lirik lagu karya Iwan Fals dalam penelitian ini mendeskripsikan kritikan kepada pemerintah yang kurang mempedulikan kesejahteraan rakyatnya. Hal ini dapat dilihat pada lirik lagu yang diteliti, yakni "Tikus-tikus Kantor" (1984), "Galang rambu anarki”" (1982), "Orang Pinggiran" (1995 "Sarjana Muda"(1981) dan "Surat Buat Wakil Rakyat"(1987). Masalah yang diungkapkan dalam lirik lagu tersebut adalah kritik sosial yang terdiri dari masalah korupsi, penegak hukum, kemiskinan, pengangguran, dan kolusi. Kemudian, cara untuk menyampaikan kritikan sosial tersebut, pengarang menggunakan gaya bahasa metafora, personifikasi, alusi, dan antitesis.

\section{Daftar Pustaka}

Agustina, Dadan Eva. 2004. "Vidio Klip Sebagai Interpestasi Lirik Lagu" (Analisis Semiotik Lagu 'Ancur' yang di Nyanyikan oleh Iwan Fals). Skripsi. Universitas Muhammadiayah Malang. Aisah Siti. 2010. "Ungkapan Metaforis Lirik Lagu Remaja (Studi Kasus pada Lirik-lirik Lagu Iwan Fals)". Skripsi. Yogyakarta: Universitas Gadjah Mada Yogyakarta.

Aminuddin. 1990. Pengembangan Penelitian Kualitatif dalam Bidang Bahasa dan Sastra. Malang: Yayasan Asih Asuh. Nagakawa. 2000. Musik dan Etimologi. Jakarta: Yayasan Obor Indonesia.

Fals, Iwan. 2007. Nyanyian Di Tengah Kegelapan. Yogyakarta: Penerbit Ombak.

http.// www.Iwan Fals.co.id diakses tanggal 2 Desember 2014.

http.//www.Iwan Fals Wikipediaensiklopedia bahasa Indonesia bebas.com diakses 2 Desember 2014.

http://www.academia.edu/6488022/Maka lah_Semantik. Di akses tanggal 5

Desember 2014. 